Original Article

\title{
Analysis of cortical activation during three types of therapeutic activity
}

\author{
Seong-A Lee, OT, PhD ${ }^{1)}$, Sang-Heon Lee, OT, PhD ${ }^{1)}$, Bong-Keun Jung, OTR, OTD ${ }^{1)^{*}}$ \\ 1) Department of Occupational Therapy, College of Medical Science, Soonchunhyang University: \\ Soonchunhyang ro 22, Shinchang-myeon, Asan-si, Republic of Korea
}

\begin{abstract}
Purpose] The objective of this study was to investigate changes from resting of the evoked cortical activity when participants performed three levels of therapeutic activities. [Subjects and Methods] Twenty-five students participated in this study. Changes in the amplitude of 16 pairs of evoked potentials were compared for three different activities: adjunctive, enabling, and purposeful. Data were analyzed using descriptive statistics and one-way ANOVA. [Results] Significant differences were found among the selected three activities for the Alpha 1 waveform. The complexity hierarchy was confirmed by descriptive statistics, as well as analyses of the three brain regions: central position (motor) Beta 1; parietal lobes, Beta 2, and occipital lobes, Alpha 1. In each instance, purposeful activity was confirmed as the most complex activity, followed by enabling, and then adjunctive. [Conclusion] This study will provide rehabilitation professionals with valuable information regarding what type of activity they should choose for a correct level of therapeutic challenge when they work with patients to plan meaningful interventions.
\end{abstract}

Key words: Therapeutic activities, Cortical activation, EEG

(This article was submitted Oct. 21, 2014, and was accepted Dec. 16, 2014)

\section{INTRODUCTION}

People engage in many different activities as part of their life roles in activities of daily living and the pursuit of wellbeing ${ }^{1)}$. A tenet of occupational therapy is to use activities as a means of achieving rehabilitation. However, not all activities provide the same level of challenge, or meet the current needs of the patient. Pedretti identified a hierarchy of activities that therapists can consider when they are working with patients to identify the most appropriate intervention strategies for the patients' current status ${ }^{2}$. By considering Pedretti's hierarchy, the proposed intervention activities and the skills a patient needs to acquire, the activity becomes therapeutic.

Pedretti describes four levels of activity that can guide intervention strategies by using real objects, environments, and meaningful occupations: adjunctive, enabling, purposeful, and occupation-based ${ }^{2}$. Adjunctive activities focus on facilitating or inhibiting motion, and preparing patients for more intentional activities. Enabling activities prepare patients for purposeful activity by simulating purposeful activities and practicing the sequential steps of a purposeful activity, and they are meant to engage the mental and

*Corresponding author. Bong-Keun Jung (E-mail: jungb@ sch.ac.kr)

C2015 The Society of Physical Therapy Science. Published by IPEC Inc. This is an open-access article distributed under the terms of the Creative Commons Attribution Non-Commercial No Derivatives (by-ncnd) License $<$ http://creativecommons.org/licenses/by-nc-nd/3.0/>. physical participation of the patient ${ }^{3}$. Purposeful activities have a meaningful goal for the patient and focus on specific self-care, home management, work, or leisure tasks that are relevant to what the patient wants to do, needs to do, or is expected to $\mathrm{do}^{5,18)}$. Occupation-based activities are purposeful activities carried out in the "lived in" environment or community, and thus have ecological validity for the patient. This dynamic interaction among the patient, the therapeutic activity, and the environment is consistent with the foundational framework provided by the therapeutic task-oriented approach $^{3,17)}$

The hierarchical approach to activity is supported by basic and applied neuroscience concepts that imply that skilled interaction associated with a client's activity performance in a particular environment may facilitate cortical activation and lead to performance changes ${ }^{3}$. In addition, the hierarchy of the activities that involve hand movements at a particular level may lead the change of the brain activation ${ }^{4}$.

Electroencephalograms (EEGs) show brain surface electrical activity at various sites on the scalp, depicting the electrical activity in waveforms, which vary in frequency, amplitude and current. EEG measurement is easy and noninvasive. The most common classification of waveform frequencies are delta, theta, alpha and beta ${ }^{6}$, which represent different levels of arousal. Delta $(\delta)$ waves $(0.5-3 \mathrm{~Hz}$ range), are commonly associated with low physical energy and sleep, and theta $(\theta)$ waves ( $4-8 \mathrm{~Hz}$ range) are consistent with drowsiness. Alpha $(\alpha)$ waves $(8-13 \mathrm{~Hz}$ range) are associated with inhibition/facilitation and timing across brain locations. The $\beta 1$ wave forms $(12-15 \mathrm{~Hz}$ range) are associated with motor function, and beta $2(\beta 2)$ waves $(15-30 \mathrm{~Hz}$ range) are 
associated with alertness and active thought $\left.{ }^{7}, 8\right)$. Brain regions typically sampled during EEG using the international 10-20 system are: the frontal lobe (conscious thought), the central position (motor function and motor imagery), the parietal lobe (sensory motor), the occipital lobe (vision), and the temporal lobe (smell, sound, faces, scenes) ${ }^{13}, 14$ ). The purpose of this study was to identify brain activity changes from the resting state in select cortical areas, in students who performed activities at three levels of Pedretti's hierarchy: adjunctive, enabling, and purposeful.

\section{SUBJECTS AND METHODS}

The design was a single cohort study comparing cortical brain activities measured by EEG adjunctive (finger movement), enabling (finger painting), and purposeful (complete a pegboard work task) activities. Waveforms were delimited to Alpha 1 (inhibition/facilitation/ timing), Beta 1 (motor function), and Beta 2 (alertness, active thought).

The participants were 25 occupational therapy undergraduate students attending Soonchunhyang University, 8 males $(38 \%)$ and 13 females $(62 \%)$, with a mean age of 22.23 years $(\mathrm{SD}=1.34)$. This study was approved by the institutional review board of Soonchunhyang University (IRB No.1040875-201403-BM-004), and all participants provided their informed consent before participation. Students were enrolled in Year 2 of their curriculum, but had not yet been taught Pedretti's hierarchy.

A third generation Degital EEG \& EP Brain Mapping System (Intermed Co., Ltd. (South Korea), Model number: Neuronics-32 ${ }^{15)}$ was used to measure the brain cortical activities.

To identify changes in the neurophysiological characteristics of the cortex for each level of activity, evoked potentials (EPs) were recorded as indicators of the functional state of the cortical regions studied. To estimate changes in the cortical activity, the EP in response to light was recorded before testing under each condition. The EPs were measured in 16 symmetrical areas of the right and left hemispheres of the frontal lobe (FP1, FP2, F3, F4 F7, F8), parietal lobe (P3, $\mathrm{P} 4)$, central position $(\mathrm{C} 3, \mathrm{C} 4)$, occipital lobe $(\mathrm{O} 1, \mathrm{O} 2)$. and temporal lobe (T3, T4, T5 and T6) in the monopolar mode according to the international $10-20$ system $^{14)}$. The stimuli were flashes of light of medium intensity $(0.4 \mathrm{~J})$ with an exposure time of $50 \mu \mathrm{s}$ and frequency of $256 \mathrm{~Hz}$.

Students performed the activity associated with each condition for 5 minutes, and left/right EPs were recorded for 2 minutes and front/back were each recorded for 1 minute and 30 seconds. Twenty-five participant responses to EEG epochs of the three activities were averaged in each case. Amplitude changes from the resting state were coded as the level of cortical activation energy for analysis. Descriptive statistics and one-way ANOVA were used to analyze the data, focusing on Alpha 1, Beta 1 and Beta 2 waveforms under the three conditions.
Table 1. Cortical changes from resting, by brain waveform and level of activity

\begin{tabular}{cccc}
\hline Brain waveform & $\begin{array}{c}\text { Adjunctive } \\
\text { Mean (SD) }\end{array}$ & $\begin{array}{c}\text { Enabling } \\
\text { Mean (SD) }\end{array}$ & $\begin{array}{c}\text { Purposeful } \\
\text { Mean (SD) }\end{array}$ \\
\hline Alpha 1* & $25.95(6.8)$ & $24.54(4.9)$ & $30.04(5.5)$ \\
Beta 1 & $18.93(5.2)$ & $18.42(2.6)$ & $20.25(2.9)$ \\
Beta 2 & $18.24(4.4)$ & $17.55(2.3)$ & $20.11(3.2)$ \\
\hline
\end{tabular}

\section{RESULTS}

Brain activity changes from the resting state were examined in students who performed adjunctive, enabling, and purposeful activities. Significant differences among the three activities were found only for the Alpha 1 waveforms. No significant differences among the activities were found for Beta 1 or Beta 2 waveforms (Table 1). Table 2 displays the 16 EEG sites and the cortical activations of each activity. Differences among the activities by brain region were significant for the central position for Betal waveforms (purposeful $>$ adjunctive), parietal lobes for Beta 2 waveforms (enabling $>$ adjunctive), and occipital lobes for Alpha 1 waveforms (purposeful $>$ enabling) (Table 3). No significant differences were found for the frontal or temporal lobes.

\section{DISCUSSION}

Although significant differences among waveforms of the three activities were only found for Alpha 1, the more complex purposeful activity always showed greater cortical activation for each waveform. Moreover, the adjunctive activity of simple finger movement consistently stimulated cortical activation more than the enabling activity of finger painting. This may reflect a lack of concentration in moving the individual fingers when finger painting with the whole hand. It could also indicate that finger painting was not a good choice for the enabling activity.

Pedretti's hierarchy ${ }^{2}$ was confirmed by our brain region analyses. In each of the brain regions (i.e., central, parietal, occipital) where significant differences were observed among the activities, more complex activity generated greater cortical activation than less complex activity. When specific EEG sites were examined, the hierarchy was also upheld. For example, for Alpha 1 waveforms, activation was the greatest for purposeful (13 times), followed by enabling ( 2 times), and adjunctive (1 time) activities. Although Beta 1 showed the greatest activity in purposeful activities (6 times), the enabling and adjunctive activities were tied (5 times each). However, for Beta 2, purposeful activities again showed the greatest activity 9 times, followed by enabling ( 4 times), and adjunctive (3 times) activities.

A review of brain region function also supports the activity hierarchy ${ }^{16)}$. Each of the tasks required finger movement and upper extremity movement, which was captured by the central position Beta 1 differences, with the purposeful activity reflecting significantly greater $\mathrm{C} 3-\mathrm{C} 4$ motor and motor imagery activation than the adjunctive activity ${ }^{11,12)}$. Similarly, the sensory-motor parietal lobe Beta 2 analyses 
Table 2. Brain waveforms by EEG site and activity

\begin{tabular}{|c|c|c|c|c|}
\hline \multirow{2}{*}{$\begin{array}{l}\text { Brain } \\
\text { waveform }\end{array}$} & \multirow{2}{*}{ EEG site } & \multicolumn{3}{|c|}{ Activity condition } \\
\hline & & Adjunctive & Enabling & Purposeful \\
\hline \multirow[t]{17}{*}{ Alpha 1} & FP1 & 33.3 & 30.7 & 37.5 \\
\hline & FP2 & 35.1 & 34.5 & 38.4 \\
\hline & F3 & 16.7 & 20.2 & 25.0 \\
\hline & $\mathrm{F} 4$ & 18.5 & 24.0 & 23.0 \\
\hline & $\mathrm{C} 3$ & 18.6 & 18.1 & 32.6 \\
\hline & $\mathrm{C} 4$ & 19.7 & 19.6 & 27.8 \\
\hline & P3 & 22.0 & 25.2 & 26.7 \\
\hline & P4 & 22.7 & 22.5 & 25.2 \\
\hline & $\mathrm{O} 1$ & 31.9 & 24.3 & 34.9 \\
\hline & $\mathrm{O} 2$ & 33.2 & 24.5 & 34.6 \\
\hline & F7 & 39.0 & 30.6 & 31.3 \\
\hline & F8 & 29.8 & 31.8 & 31.4 \\
\hline & $\mathrm{T} 3$ & 22.4 & 19.9 & 22.4 \\
\hline & $\mathrm{T} 4$ & 22.9 & 20.5 & 23.1 \\
\hline & T5 & 23.5 & 22.4 & 37.1 \\
\hline & $\mathrm{T} 6$ & 25.9 & 23.9 & 29.6 \\
\hline & Average & 25.95 & 24.54 & 30.04 \\
\hline \multirow[t]{10}{*}{ Beta 1} & FP1 & 20.4 & 18.5 & 22.2 \\
\hline & FP2 & 28.3 & 21.9 & 24.1 \\
\hline & F3 & 13.2 & 14.3 & 17.2 \\
\hline & $\mathrm{F} 4$ & 14.8 & 18.3 & 17.3 \\
\hline & $\mathrm{C} 3$ & 15.3 & 13.5 & 22.7 \\
\hline & $\mathrm{C} 4$ & 16.4 & 17.3 & 21.7 \\
\hline & P3 & 15.5 & 18.0 & 17.7 \\
\hline & P4 & 16.5 & 19.5 & 17.2 \\
\hline & O1 & 18.9 & 19.5 & 22.0 \\
\hline & $\mathrm{O} 2$ & 23.3 & 21.7 & 23.0 \\
\hline
\end{tabular}

Table 2. Continued

\begin{tabular}{|c|c|c|c|c|}
\hline \multirow{2}{*}{$\begin{array}{l}\text { Brain } \\
\text { waveform }\end{array}$} & \multirow{2}{*}{ EEG site } & \multicolumn{3}{|c|}{ Activity condition } \\
\hline & & Adjunctive & Enabling & Purposefu \\
\hline \multirow{24}{*}{ Beta 2} & F7 & 31.4 & 20.2 & 19.7 \\
\hline & F8 & 24.2 & 20.4 & 22.3 \\
\hline & $\mathrm{T} 3$ & 16.7 & 13.8 & 15.7 \\
\hline & $\mathrm{T} 4$ & 15.7 & 18.7 & 16.9 \\
\hline & T5 & 15.2 & 18.1 & 24.3 \\
\hline & $\mathrm{T} 6$ & 17.0 & 21.0 & 20.0 \\
\hline & Average & 18.93 & 18.42 & 20.25 \\
\hline & FP1 & 23.2 & 19.5 & 22.7 \\
\hline & FP2 & 28.2 & 20.1 & 25.6 \\
\hline & F3 & 13.4 & 14.6 & 16.7 \\
\hline & $\mathrm{F} 4$ & 16.0 & 16.5 & 17.3 \\
\hline & $\mathrm{C} 3$ & 14.1 & 13.6 & 19.7 \\
\hline & $\mathrm{C} 4$ & 14.6 & 14.6 & 19.6 \\
\hline & P3 & 15.5 & 17.2 & 16.6 \\
\hline & P4 & 15.4 & 17.3 & 17.2 \\
\hline & $\mathrm{O} 1$ & 18.5 & 19.0 & 23.0 \\
\hline & $\mathrm{O} 2$ & 19.7 & 20.4 & 21.4 \\
\hline & F7 & 25.4 & 18.5 & 21.2 \\
\hline & F8 & 23.1 & 20.6 & 23.8 \\
\hline & $\mathrm{T} 3$ & 15.6 & 14.6 & 16.0 \\
\hline & $\mathrm{T} 4$ & 16.0 & 17.6 & 16.9 \\
\hline & $\mathrm{T} 5$ & 16.4 & 17.2 & 24.7 \\
\hline & $\mathrm{T} 6$ & 16.7 & 19.5 & 19.4 \\
\hline & Average & 18.24 & 17.55 & 20.11 \\
\hline
\end{tabular}

Italics $=$ greatest average cortical activity

F, FP: frontal lobe, C: central position, P: parietal lobe, O: occipital lobe, T: temporal lobe

Table 3. Cortical regions with significant differences among the activities

\begin{tabular}{llcccc}
\hline Cortical region & & Sum of squares & df & Mean square & Difference between conditions \\
\hline Central position* & Between groups & 57.84 & 2 & 28.92 & $3>1$ \\
(C3-C4) & Within groups & 8.33 & 3 & 2.78 & \\
Beta 1 & Total & 66.17 & 5 & & $2>1$ \\
Parietal lobes* & Between groups & 3.64 & 2 & 1.82 & \\
Beta 2 & Within groups & 0.19 & 3 & 0.06 & $3>2$ \\
& Total & 3.83 & 5 & & \\
Occipital lobes* & Between groups & 118.92 & 2 & 49.46 & \\
Alpha 1 & Within groups & 0.91 & 3 & 0.30 & \\
& Total & 119.83 & 5 & & \\
\hline
\end{tabular}

$* \mathrm{p}<0.05$

Conditions: 1 = Adjunctive, 2 = Enabling, 3 = Purposeful

reflected the significantly greater cortical activity observed when students performed the enabling activity (finger painting) than the adjunctive activity (finger movement). Certainly finger painting provides more sensory input that finger movement alone, and creating a picture or design with finger paint also requires Beta 2 active thought. Finally, the significantly greater activation of the Alpha 1 waveforms in the occipital lobe region (vision) would be explained by the purposeful activity of placing pegs in a grid requiring visual vigilance compared to the enabling activity of finger painting. Although the frontal lobe, center of conscious thought showed high activation during each activity, there were no 
significant differences among the conditions. Similarly, the temporal lobe, which processes smell, sound, faces and scenery, showed moderate activation during each activity, but there were no significant differences among them.

Our findings are consistent with those of Steinbeck ${ }^{5}$ ) and $\mathrm{Heck}^{16)}$. Steinbeck found that a participants completed significantly more repetitions of purposeful activities (drilling to make a Hi-Q game; an adapted ping pong game) than non-purposeful activities using the same muscle groups and levels of exertion. Similarly, Heck found that participants could tolerate pain for significantly longer periods of time when engaged in a purposeful activity (duplicating a complex design by marking an X over each square of the design) versus a non-purposeful activity (making an X over and over in the same space). In contrast to our findings, Shibaski ${ }^{9)}$ found that a hand task activated the parietal lobes, whereas our findings showed greater activation of C3-C4. Somewhat similar to our findings, Aghababyan et al. ${ }^{10)}$ found greater frontal, temporo-parieto-occipital activation during a creative task.

As with all studies, this study had limitations. The number of students was small, and further studies should recruit greater numbers of participants. It is also questionable whether the finger painting task was the best choice for the enabling activity; however, our data indicate that it confirmed the hierarchy except for the Beta 1 waveform. This study added to the body of knowledge by providing confirmatory evidence of Pedretti's hierarchy of activity challenges. Rehabilitation therapists can use Pedretti's hierarchy to plan activities with sequentially greater challenges in order to best meet the needs of their patients.

\section{ACKNOWLEDGEMENTS}

This study was supported by the Soonchunhyang University Research Fund and the MSIP (Ministry of Science, ICT and Future Planning), Korea, under the C-ITRC (Convergence Information Technology Research Center) support program (IITP-2015-H8601-15-1009) supervised by the IITP (Institute for Information \& Communications Technology Promotion).

\section{REFERENCES}

1) American Occupational Therapy Association: Occupational therapy practice framework: Domain and process, 3rd ed. Am J Occup Ther, 2014, 68, S1-S48. http://dx.doi.org/. [CrossRef]

2) Pendleton HM, Schultz-Krohn W: Pedretti's Occupational Therapy: Practice Skills for Physical Dysfunction. Atlanta: Mosby Elsevier, 2006.

3) Mathiowetz V, Haugen JB: Motor behavior research: implications for therapeutic approaches to central nervous system dysfunction. Am J Occup Ther, 1994, 48: 733-745. [Medline] [CrossRef]

4) Hong JH, Jang SH: Neural network related to hand movement: a combined study of diffusion tensor tractography and functional MRI. J Phys Ther Sci, 2011, 23: 97-101. [CrossRef]

5) Steinbeck TM: Purposeful activity and performance. Am J Occup Ther, 1986, 40: 529-534. [Medline] [CrossRef]

6) Niedermeyer E, Lopes da Silva F: Electroencephalography: Basic Principles, Clinical Applications, and Related Fields, 5th ed. Baltimore: Williams \& Wilkins, 1993.

7) Lundy-Ekman L: Neuroscience: Fundamentals for rehabilitation, 2nd ed. St. Louis: Elesvier Saunders, 2002.

8) Orme-Johnson DW, Haynes CT: EEG phase coherence, pure consciousness, creativity, and TM-Sidhi experiences. Int J Neurosci, 1981, 13: 211-217. [Medline] [CrossRef]

9) Shibasaki H: Cortical activities associated with voluntary movements and involuntary movements. Clin Neurophysiol, 2012, 123: 229-243. [Medline] [CrossRef]

10) Aghababyan AR, Grigoryan VG, Stepanyan A, et al.: EEG reactions during creative activity. Hum Physiol, 2007, 33: 252-253. [CrossRef]

11) Petsche H, Kaplan S, von Stein A, et al.: The possible meaning of the upper and lower alpha frequency ranges for cognitive and creative tasks. Int J Psychophysiol, 1997, 26: 77-97. [Medline] [CrossRef]

12) Martindale $C$, Hines $D$ : Creativity and cortical activation during creative, intellectual and EEG feedback tasks. Biol Psychol, 1975, 3: 91-100. [Medline] [CrossRef]

13) Wang $\mathrm{Y}$, Hong B, Gao X, et al.: Phase synchrony measurement in motor cortex for classifying single-trial EEG during motor imagery. Proceedings of the 28th IEEE. New York: 30 August, 2006, pp 75-78.

14) Wang $Y$, Hong B, Gao X, et al.: Design of electrode layout for motor imagery based brain-computer interface. Elec Lett, 2007, 43: 557-558. [CrossRef]

15) Intermed: Manual of Neuronic 32, 2010. http://www.intermed.co.kr/eng/ com01.html (Accessed Dec. 10, 2014)

16) Heck SA: The effect of purposeful activity on pain tolerance. Am J Occup Ther, 1988, 42: 577-581. [Medline] [CrossRef]

17) Kandel ER, Schwartz JH, Jessell TM, et al.: Principles of Neural Science, 5th ed. New York: McGraw-Hill, 2013, pp 5-39.

18) Kamioka Y, Yoshino T, Sugaya K, et al.: Goal-setting method and goal attainment measures in physical therapy for stroke patients: a systematic review. J Phys Ther Sci, 2009, 21: 399-415. [CrossRef] 